\title{
Determination of Silver by Fire Assay Gravimetry Combined with Mathmetic Correction
}

\author{
Sheng Jianlin *, Sun Yin, Zhu Wujin, Zeng Zongjie, Ma Guoqiang, He Hucheng, He Mingdong \\ Testing Center of Zhejiang Fuye Group Co, Ltd, Fuyang, China \\ Email address: \\ 2513472833@qq.com (Sheng Jianlin) \\ ${ }^{*}$ Corresponding author
}

\section{To cite this article:}

Sheng Jianlin, Sun Yin, Zhu Wujin, Zeng Zongjie, Ma Guoqiang, He Hu-cheng, He Ming-dong. Determination of Silver by Fire Assay Gravimetry Combined with Mathmetic Correction. International Journal of Mineral Processing and Extractive Metallurgy.

Vol. 3, No. 3, 2018, pp. 65-75. doi: 10.11648/j.ijmpem.20180303.13

Received: July 20, 2018; Accepted: October 15, 2018; Published: November 29, 2018

\begin{abstract}
The fire assay gravimetry is an old and classical method. It is one of most commonly used and most effective methods for the separation and analysis of precious metals due to strong representativeness, high accuracy and good stability. However, the fire assay gravimetry also has some disadvantages such as long analytical procedure and systemic lower analytical results (especially for silver). If the second or secondary assaying is use, the analytrcal procedure will be longer and the operation cost will be higher. Through the exploration and analysis of the test principle of smelting and ash blowing in the fire test analysis, under the premise of the control test analysis conditions, according to the merging silver content and lead buckle quality of one test gold, theoretically derived The mathematical model for correcting the amount of silver loss during smelting and ash blowing, and then the method of measuring the silver by the fire test weight method combined with the mathematical correction method, can completely eliminate the operation steps of the second test. The content of silver in three representative samples (including crude copper, copper concentrate and copper anode slime) was determined by the experimental method and fire assay-recovery correction method in the experiment. In the latter method, the lost silver in residue and cupel was determined by second fire assaying to obtain the corrected ralue of silver. The results showed that the relative difference between two methods were within $\pm 0.5 \%$. The relative standard deviation $(R S D)$ of crude copper $(\mathrm{n}=11)$ and copper concentrate $(\mathrm{n}=12)$ with proposed method was $0.9 \%$ and $1.2 \%$. In addition, in this article, the optimum lead button mass with various samples and assay ingredient schemes was obtained by higher mathematics derivation, and the lead button mass in national related analysis standards was reasonably and scientifically reviewed.
\end{abstract}

Keywords: Fire Assay, Gravimetry, Ingredient, Smelting, Cupellation, Lead Button Mass, Silver Loss, Mathematic Model, Correction Coefficient

\section{Introduction}

How to control the optimal degree of silicic acid according to the type and nature of the sample, and make reasonable ingredients to obtain suitable slag and good lead button mass, which is the premise of the lead tester gravimetric method for determining the success or failure of precious metal elements [1-3], and how to further improve the precision and accuracy of the lead test weight method, or how to scientifically and effectively correct the loss of precious metal elements in smelting and cupellation, which is the key to perfecting the lead test weight method [4-9]. Among all the precious metal elements, silver has the lowest melting point and the most active chemical properties. It is easily oxidized by air or lost due to volatilization at high temperature. Therefore, the loss is more significant than other precious metal elements in both smelting and cupellation. Therefore, how to further improve the precision and accuracy of the lead gold analysis method, or how to scientifically and effectively correct the loss of silver in smelting and cupellation is particularly important and meaningful [10-12]. Based on the analysis and exploration of the basic principles of igniting and ash refining and other methods of fire test, this paper summarizes the factors affecting silver loss and their relationship, and establishes the mathematics of silver loss correction during smelting and cupellation. The model, thus 
proposed a method of measuring the silver by the lead assay gold weight method combined with the mathematical correction method. The experimental method was applied to the analysis of three kinds of actual samples such as crude copper, copper concentrate and copper anode mud. The results show that the mathematical model of the silver loss law established by the experiment can be completely saved in the case of the second test. The loss of silver in slag and ash in blister, copper concentrate and copper anode mud samples is scientifically and effectively corrected. The experimental method not only theoretically reveals the quantitative rule of silver loss in the process of lead assay analysis, but also enriches and perfects the analysis theory and method essentials of fire test gold measurement.

\section{Theoretical Part}

\subsection{Smelting Stage}

\subsubsection{Enrichment Principle and Function of Smelting Process}

The principle of enriching the precious metals in the sample at the melting stage of the lead assay method is based on the decomposition of the mineral or matrix components of the sample on the one hand, that is, the various acid / alkaline flux, oxidizer or reductant, which are added in the sample and the ingredients, and in turn, through various dissociation (decomposition) reactions and redox reactions. The slag reacting to make most of the non precious metals to produce flusible slag by reacting the slag, while the noble metal is converted into a single form; on the other hand, lead oxide produces a large amount of the amount of precious metals in the sample (for the amount of precious metals in the sample). The droplets of metal lead form a "lead rain", and the molten metal lead has a strong affinity to the precious metals of the single substance, thus making an effective collection of precious metals, forming an alloy (called coarse lead) [1-2]. Because of the dissolubility between the coarse lead and the slag and the difference in the density, the coarse lead in the molten state is deposited at the bottom of the crucible of the test gold crucible, which is cooled to a buckle (called the lead button mass) and is separated from the slag.

\subsubsection{The Hypothesis of Melting Loss}

Although there is a great affinity between the precious metals and the molten lead (this is the theoretical basis for the enrichment of precious metals in fire test), it is not likely to be caught $100 \%$ by lead button masss, and a relatively small amount of precious metals have been dissolved in the slag, as although a large number of non precious metals are separated by slag, there are always a small amount of it. The heavy metals such as copper, bismuth, antimony and tellurium are the same as the lead button masss. Although there is a high temperature volatilization loss in the process of melting of precious metals, especially the low melting point of silver and the active chemical properties of the other precious metals, the volatilization of silver chloride is increased by the formation of silver chloride, but the loss of volatilization is relative to the amount of loss in the slag. It is always a minor [1-2], which is usually ignored because it can't be effectively recycled or measured in the actual test.

The loss of silver in the slag is mainly determined by the degree of dissolubility (the distribution coefficient $K_{\mathrm{D}}$ ) and its relative mass of the silver in the melt lead and the slag. In general, the lower the density of slag, low melting point, good fluidity and uniform texture, the lower the content of heavy metals such as lead, copper, bismuth and tellurium, the smaller the affinity of molten slag to precious metals, the smaller the solubility of silver in the slag. In addition, as the silicon acid degree $K$ ( $K$ is used to represent the relative proportion of the acid components (nonmetallic oxides) in the molten slag with the alkaline component (metal oxide), the meaning is that the total amount of oxygen in the acid oxide in the slag and the ratio of the total amount of oxygen in the alkaline oxide) is smaller, and the heavy metal elements in the slag (such as lead, copper, zinc, etc.) are in the slag. The proportion of the slag increases, and the density of the slag is increased by $\rho_{2}$. In addition, with the increase of heavy metal elements in the slag, the heavy metal elements in the lead button mass also increase, which makes the lead wet the property of precious metals worse (that is, the affinity of the parent force descends), and the enrichment effect is reduced, so the $K_{\mathrm{D}}$ decreases.

\subsubsection{Silver Loss and Establishment of Mathematical Model}

At high temperature, if metal lead and slag in the molten state are treated as two insoluble solvents, and assuming that under certain proportioning and melting conditions, the solute silver is assigned to the above two solvents. When the equilibrium is reached, the equilibrium concentration in the melt lead and the slag phase is $C_{1}\left(\mathrm{mg} / \mathrm{cm}^{3}\right)$ and $C_{2}\left(\mathrm{mg} / \mathrm{cm}^{3}\right)$ respectively. If the silver content in the sample is $X_{0}(\mathrm{mg})$ and the loss amount of silver in the slag is $Y_{1}(\mathrm{mg})$, the high temperature volatilization loss of silver is $Y_{1}{ }^{\prime}(\mathrm{mg})$, the mass of the lead button mass is $W(\mathrm{~g})$, the density is $\rho_{1}\left(\mathrm{~g} / \mathrm{cm}^{3}\right)$, the slag quality is $Z(\mathrm{~g})$ and the density is $\rho_{2}\left(\mathrm{~g} / \mathrm{cm}^{3}\right)$.

$$
\begin{gathered}
\because \mathrm{Y}_{1}{ }^{\prime}<<\mathrm{Y}_{1}<<\mathrm{X}_{0} \\
\therefore \mathrm{X}_{1}=\mathrm{X}_{0}-\mathrm{Y}_{1}-\mathrm{Y}_{1}{ }^{\prime} \approx \mathrm{X}_{0}-\mathrm{Y}_{1} \\
\therefore \mathrm{C}_{1}=\rho_{1} \times \mathrm{X}_{1} / \mathrm{W}=\rho_{1} \times\left(\mathrm{X}_{0}-\mathrm{Y}_{1}\right) / \mathrm{W} ; \mathrm{C}_{2}=\rho_{2} \times \mathrm{Y}_{1} / \mathrm{Z}
\end{gathered}
$$

According to the basic principle of solvent extraction, the partition coefficient (KD) of solute silver in molten lead and slag phases is:

$$
\begin{gathered}
\mathrm{K}_{\mathrm{D}}=\mathrm{C}_{1} / \mathrm{C}_{2}=\left[\rho_{1} \times\left(\mathrm{X}_{0}-\mathrm{Y}_{1}\right) \times \mathrm{Z}\right] /\left(\rho_{2} \times \mathrm{Y}_{1} \times \mathrm{W}\right) \\
\therefore \mathrm{Y}_{1}=\rho_{1} \times \mathrm{Z} \times \mathrm{X}_{0} /\left(\rho_{2} \times \mathrm{W} \times \mathrm{K}_{\mathrm{D}}+\rho_{1} \times \mathrm{Z}\right)
\end{gathered}
$$

In the formula, $\rho_{1}$ is constant, $\rho_{2}$ and $K_{D}$ are related to the composition and properties of the slag. If the sample, the blending scheme and the melting condition are determined, $\mathrm{X}_{0}$ is a fixed value, $\rho_{2}$ and $K_{D}$ are also constant in theory, so the loss of silver in the slag is mainly determined by the mass ratio of the melting lead and the slag (W/Z).

At the same time, the quality of the slag $(Z)$ has a certain 
relationship with the quality of the lead button mass (W), because the lead oxide added in the ingredients is mainly used in two aspects: the first is the reductive agent and the two is the slag as the alkaline flux. If all the lead oxide added in the ingredients is used for making slag, the amount of slag produced is $Z_{0}(\mathrm{~g})$. When the lead is $\mathrm{W}(\mathrm{g})$, the amount of the slag is

$$
\mathrm{Z}=\mathrm{Z}_{0}-1.077 \times \mathrm{W}
$$

The formula (3): 1.077 conversion of $\mathrm{Pb}$ into $\mathrm{PbO}$ conversion factor. When the sample and ingredient plan is determined, $\mathrm{Z}_{0}$ is constant, so $\mathrm{W}$ is small, $\mathrm{Z}$ is large, otherwise, when $\mathrm{W}$ is too large, $\mathrm{Z}$ is smaller.

If set up

$$
\mathrm{J}=\rho_{2} / \rho_{1} \times K_{D}
$$

In addition, the formula (3) and (4) are replaced (2) and finished:

$$
Y_{1}=\frac{Z_{0}-1.077 \times W}{Z_{0}+(J-1.077) \times W} \times X_{0}
$$

The formula (5) can be obtained, and the calculation formula of the loss correction coefficient of the loss of silver smelting is as follows:

$$
\lambda_{1}=\frac{X_{0}}{X_{1}}=\frac{X_{0}}{X_{0}-Y_{1}}=1+\frac{Z_{0}}{W \times J}-\frac{1.077}{J}
$$

The formula (6): $\mathrm{J}$ is a characteristic coefficient reflecting the difference between melting lead and slag on precious metals. Its size is determined by the composition and properties of the slag (i.e., $\rho_{2}, K_{D}$ ), and has nothing to do with its quantity. The $Z_{0}$ and $J$ are constant when the sample, the formula and the melting condition are determined. Obviously, when $\mathrm{W}$ is reduced, both $\mathrm{Y}_{1}$ and $\lambda_{1}$ increase, and vice versa. In addition $\lambda_{1}$ is only related to the actual quality of the lead button mass, but has nothing to do with the content of silver in the sample.

\subsection{Stage of Cupellation}

\subsubsection{The Principle and Function of the Cupellation Process}

The theoretical basis of the cupellation is the preferential oxidation of the molten non precious metals on the surface of the molten body and the preferential wetting effect of the molten oxide on the ash. The basic principle is that, because the ash is a semi permeable mineral, under the action of its capillary force, it can make the molten lead oxide and other metal oxides infiltrate and be absorbed by the gray dish, and the precious metal is not easy to oxidize, but it is still on the gray dish. This makes the precious metal elements in the lead button mass effectively separate [1-3] rom a large number of lead and a small amount of non precious metals, which are fused to lead.

As silver is the most precious metal element with the most active chemical properties and the lowest melting point, silver is more vulnerable to oxidation or volatilization than other precious metals in the process of cupellation. Most of the silver loss is scattered on the surface of the gray dish or in the inside of the ash. The loss of silver is only a small part because of the volatilization, which accounts for about $8 \sim 10 \%[1,2]$ of the total ash loss.

\subsubsection{The Hypothesis of the Loss of Cupellation}

In the process of blowing, lead is always liquid and silver melted evenly. Therefore, the silver, exposed to the surface of the molten body, may be oxidized by air and lost with the ash of lead oxide; the two, because the melting point of the silver is $960^{\circ} \mathrm{C}$, and the cupellation temperature is $850 \sim 880^{\circ} \mathrm{C}$ may solidify with the cooling and be dispersed on the surface of the ash. On the other hand, the temperature of the molten body is much higher than that on the surface of the molten body because of the oxidation and exothermic of lead. The silver that solidifies on the surface of the molten body may be remelted and entered into the molten body because of cooling and cooling, thus reducing the loss of the Silver blowing. A small amount of silver lost in high temperature volatilization during the cupellation process is usually neglected because of its ineffective recovery in practical tests.

It is assumed that the surface area of the molten body is $\mathrm{S}$ (cm), and the concentration of silver in the molten body is $\mathrm{C}$ $\left(\mathrm{mg} / \mathrm{cm}^{3}\right)$, because the oxidation rate of silver $\mathrm{V}_{1}(\mathrm{mg} / \mathrm{min})$ is proportional to the chance that the silver molecules are exposed to the surface of the molten body and the air contact, which is proportional to the product of $\mathrm{S}$ and $\mathrm{C}$. If the ratio coefficient is $\mathrm{k}_{1}(\mathrm{~cm} / \mathrm{min})$, then:

$$
\mathrm{V}_{1}=\mathrm{k}_{1} \times \mathrm{S} \times \mathrm{C}
$$

The solidification loss is caused by the combined action of cooling force and diffusion force. The effect of cold force is related to the speed of the cupellation, which is proportional to the upper surface area of the molten body S, and the effect of the diffusion force is directly proportional to the concentration of silver in the molten body $\mathrm{C}$. The solidification rate $\mathrm{V}_{2}$ $\mathrm{mg} / \mathrm{min}$ ) is also proportional to the product of $\mathrm{S}$ and $\mathrm{C}$. If the ratio coefficient is $\mathrm{k}_{2}(\mathrm{~cm} / \mathrm{min})$, then:

$$
\mathrm{V}_{2}=\mathrm{k}_{2} \times \mathrm{S} \times \mathrm{C}
$$

The melting rate $V_{3}(\mathrm{mg} / \mathrm{min})$ is proportional to the amount of silver that may be precipitated in the unit time, which is directly proportional to the solidification rate of $\mathrm{V}_{2}$, because of the effect of cold and diffusion force in the unit time. If the ratio coefficient is $\mathrm{k}_{3}$, then:

$$
\mathrm{V}_{3}=\mathrm{k}_{3} \times \mathrm{V}_{2}=\mathrm{k}_{3} \times \mathrm{k}_{2} \times \mathrm{S} \times \mathrm{C}
$$

The amount of gray blowing loss of silver is caused by the interaction of factors such as $\mathrm{V}_{1}, \mathrm{~V}_{2}$ and $\mathrm{V}_{3}$ in the cupellation.

\subsubsection{The Establishment of a Mathematical Model of Silver Loss}

If the surface tension is ignored on the surface shape of the 
lead molten body, a hemispherical dish (see Figure 1) has a radius of $R(\mathrm{~cm})$, the surface radius of the molten body is $r$ $(\mathrm{cm})$, the height is $\mathrm{h}(\mathrm{cm})$, the volume is $\mathrm{U}\left(\mathrm{cm}^{3}\right)$, and the silver content is $\mathrm{X}(\mathrm{mg})$, then:

$$
\begin{aligned}
r^{2} & =R^{2}-(R-h)^{2}=h \times(2 R-h) \\
\therefore S & =\pi \times r^{2}=\pi \times h \times(2 R-h)
\end{aligned}
$$

The volume is calculated according to the volume formula of the ball.

$$
\begin{gathered}
\mathrm{U}=\pi \times \mathrm{h}^{2} \times(\mathrm{R}-1 / 3 \times \mathrm{h})=\pi / 3 \times \mathrm{h}^{2} \times(3 \mathrm{R}-\mathrm{h}) \\
\therefore C=\frac{X}{U}=\frac{3 X}{\pi h^{2} \times(3 R-h)}
\end{gathered}
$$

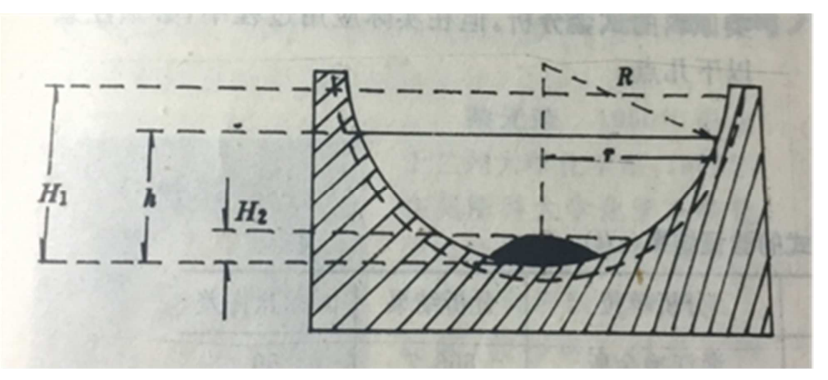

Figure 1. Schematic diagram of cupellation process.

According to the principle of higher mathematics calculus, if the integral unit of the loss of silver is set to $\mathrm{dx}$, the integral unit of the influence rate of each factor is $\mathrm{dv}$, and the time integral unit is dt, then:

$$
-\mathrm{dx}=-\mathrm{dv} \times \mathrm{dt}=-\left(\mathrm{V}_{1}+\mathrm{V}_{2}-\mathrm{V}_{3}\right) \times \mathrm{dt}=-\left(\mathrm{k}_{1}+\mathrm{k}_{2}-\mathrm{k}_{2} \times \mathrm{k}_{3}\right) \times \mathrm{S} \times \mathrm{C} \times \mathrm{dt}
$$

The formula (12) : k1 and k2 are related to the speed of cupellation, which are mainly determined by the cupellation conditions (such as cupellation temperature, furnace air volume, and ash material), while $\mathrm{k} 3$ is a positive proportional coefficient between V3 and V2, so when the conditions are determined, $\mathrm{k} 1, \mathrm{k} 2$ and $\mathrm{k} 3$ are both fixed values. If $\mathrm{k} 1+\mathrm{k} 2$ $-\mathrm{k} 2 \times \mathrm{k} 3=\mathrm{k}, \mathrm{k}$ is a constant $(\mathrm{cm} / \mathrm{min})$, which is a characteristic coefficient reflecting the condition of blowing and facilities. The formula (10), (11) is replaced (12) and finished:

$$
-\frac{1}{x} d x=-k\left(\frac{2}{h}-\frac{1}{3 R-h}\right) d t=-k\left(\frac{2}{h}-\frac{1}{3 R-h}\right) d h
$$

The lead melt is $\mathrm{H}_{1}(\mathrm{~cm})$, and the silver content is $\mathrm{X}_{1}(\mathrm{mg})$ before the ash blow, and the silver melt after the ash blow is $\mathrm{H}_{2}$ (cm), and the weight of the particle is $\mathrm{X}_{2}(\mathrm{mg})$.

$$
\begin{array}{r}
-\int_{x_{1}}^{x_{2}} \frac{1}{x} d x=-k \int_{H_{1}}^{H_{2}}\left(\frac{2}{h}-\frac{1}{3 R-h}\right) d h \\
\therefore \ln X_{1}-\ln X_{2}=-k \ln \frac{H_{2}^{2}\left(3 R-H_{2}\right)}{H_{1}^{2}\left(3 R-H_{1}\right)}+k_{0}
\end{array}
$$

The density of the re melting silver is $\rho_{3}\left(\mathrm{~g} / \mathrm{cm}^{3}\right)$. Because of $\mathrm{W}>>\mathrm{X}_{1}$, the mass and volume of silver in the lead melt are negligible, and if the gold and other precious metals are also ignored,

$$
\begin{aligned}
& \mathrm{W}=\pi / 3 \times \mathrm{H}_{1}{ }^{2} \times\left(3 \mathrm{R}-\mathrm{H}_{1}\right) \times \rho_{1} \\
& \mathrm{X}_{2}=\pi / 3 \times \mathrm{H}_{2}{ }^{2} \times\left(3 \mathrm{R}-\mathrm{H}_{2}\right) \times \rho_{3} \times 10^{3}
\end{aligned}
$$

The formula (14), (15) is replaced (13) and finished:

$$
\ln \mathrm{X}_{1}=(1-\mathrm{k}) \times \ln \mathrm{X}_{2}+\mathrm{k} \times \ln \mathrm{W}-\mathrm{k} \times \ln \left(\rho_{1} / \rho_{3} \times 10^{-3}\right)+\mathrm{k}_{0}
$$

In the formula, $\mathrm{K}_{0}$ is an integral constant, and $\mathrm{k} \times \mathrm{ln}$ $\left(\rho_{1} / \rho_{2} \times 10^{-3}\right)$ is also constant. If

$-\mathrm{k} \times \ln \left(\rho_{1} / \rho_{2} \times 10^{-3}\right)+\mathrm{k}_{0}=\mathrm{A}$, then:

$$
\ln \mathrm{X}_{1}=(1-\mathrm{k}) \times \ln \mathrm{X}_{2}+\mathrm{k} \times \ln \mathrm{W}+\mathrm{A}(0<\mathrm{k}<<1)
$$

The formula (17) can be obtained, and the calculation formula of the loss correction coefficient of the silver ash blow loss coefficient $\lambda_{2}$ is as follows:

$$
\lambda_{2}=\frac{X_{1}}{X_{2}}=e^{A}\left(\frac{W}{X_{2}}\right)^{k}=e^{\frac{A}{1-k}}\left(\frac{W}{X_{1}}\right)^{\frac{k}{1-k}}
$$

The formula (18) can be obtained, and the calculation formula for the loss of silver in the cupellation $\mathrm{Y}_{2}$ is as follows:

$$
\begin{gathered}
Y_{2}=X_{1}-X_{2}=\left[e^{A}\left(\frac{W}{X_{2}}\right)^{k}-1\right] \times X_{2}= \\
{\left[1-e^{-\frac{A}{1-k}}\left(\frac{X_{1}}{W}\right)^{\frac{k}{1-k}}\right] \times X_{1}}
\end{gathered}
$$

By formula (18) and (19), it is known that under the same grey blowing conditions, the compensation coefficient of the loss of silver in the ash blow is mainly determined by the ratio of the mass of lead to silver in the lead button mass $\left(\mathrm{W} / \mathrm{X}_{1}\right.$ or $\mathrm{W} / \mathrm{X}_{2}$ ). If the quality of the lead button mass (W) is controlled as a fixed value, $\lambda_{2}$ mainly depends on the content of the silver in the lead button mass $\left(X_{1}\right.$ or $\left.X_{2}\right)$ : when the silver content $X_{1}$ or $\mathrm{X}_{2}$ increases, $\lambda_{2}$ decreases, and the actual loss amount $\mathrm{Y}_{2}$ increases; and vice versa. If the amount of silver content $X_{1}$ or $\mathrm{X}_{2}$ is determined for the same sample, the loss rate or loss amount of silver in the cupellation process is only related to the quality of the lead button mass. When the mass $\mathrm{W}$ of the lead button mass increases, the loss rate of the ash blow increases, the correction coefficient $\lambda_{2}$ increases and the loss amount $Y_{2}$ increases because of the increase of the lead mass, and the loss amount $Y_{2}$ is increased; and vice versa.

\subsection{Application of Mathematical Correction Method in Determination of Silver in Lead Assay Fire Gold Gravimetric Method}

To sum up, the formula (6) and formula (18) can be used to deduce the formula for calculating the total loss correction coefficient of the silver in the analysis of lead test. 


$$
\lambda=\frac{X_{0}}{X_{2}}=\frac{X_{0}}{X_{1}} \times \frac{X_{1}}{X_{2}}=\lambda_{1} \times \lambda_{2} \approx \lambda_{1}+\lambda_{2}-1=e^{A}\left(\frac{W}{X_{2}}\right)^{k}+\frac{Z_{0}}{W \times J}-\frac{1.077}{J}
$$

$\mathrm{A}$ and $\mathrm{k}$ are mainly determined by the condition of cupellation, which can be obtained according to the formula (17) regression. When the cupellation temperature and the material of the ash are determined, $Z_{0}$ and $J$ are determined mainly by the sample and the formula. The $Z_{0}$ is measured by the experiment and can be calculated by the J basis formula (4), and when the sample and the ingredients are determined, $\mathrm{Z}_{0}$ and $\mathrm{J}$ is also fixed.

In actual measurement, only according to the determination data of a test gold ( $\mathrm{X}_{2}$ and $\left.\mathrm{W}\right)$, the correction coefficient (20) can be calculated first, and then the mass fraction w(Ag) of the silver in the test material can be calculated according to the formula (21), and the value is expressed in $\mathrm{g} / \mathrm{t}$.

$$
\mathrm{w}(\mathrm{Ag})=\left(\lambda \times \mathrm{X}_{2}-\mathrm{m}_{0}{ }^{\prime}\right) / \mathrm{G} \times 10^{3}
$$

In the formula: $\mathrm{Z}_{0}$ is the amount of slag produced by the lead oxide added in the ingredients, the amount of slag produced, unit $\mathrm{g}$; $\mathrm{W}$ is a test gold lead mass, unit $\mathrm{g} ; \mathrm{X}_{2}$ is the quality of silver in the grain of a test gold, unit $\mathrm{mg} ; \mathrm{m}_{0}{ }^{\prime}$ is the silver blank of the reagent added in a test gold, unit $\mathrm{mg}$; $\mathrm{G}$ is the quality of the known sample, unit $\mathrm{g}$.

\section{Experimental Part}

\subsection{The Purpose of the Experiment}

The experimental values of the physical quantities (such as $\mathrm{Z}_{0}, \mathrm{~K}_{\mathrm{D}}, \mathrm{J}, \lambda_{1}, \lambda_{2}, \lambda, \mathrm{A}, \mathrm{k}$, etc.) described above are obtained, and the objectivity and correctness of the mathematical model of the law of silver loss are verified, which is to verify the authenticity and scientificity of the lead test gold weight method combined with the mathematical correction method.

\subsection{Experimental Method}

Through the test of the same sample under two different quality lead button masss, the effect of the quality of lead button mass on the loss of silver in melting and cupellation is verified. The influence of silver content in the sample on the loss of silver in smelting and cupellation is verified through the test of two different kinds of silver content of the same sample. Law.

\subsubsection{Sample}

The weighing and accuracy of the sample are as follows: Crude copper $10 \mathrm{~g} \pm 0.01 \mathrm{~g}$, Copper concentrate $15 \mathrm{~g} \pm 0.01 \mathrm{~g}$, copper anode mud $1.00 \mathrm{~g} \pm 0.0001 \mathrm{~g}$.

3 kinds of representative different kinds of samples were selected for crude copper, copper concentrate and copper anode slime. Each sample was selected 2 samples of different silver content, total 6 samples (A to F). Each sample was divided into a trial gold test under the condition of two different lead button mass quality (each added unequal amount of starch or potassium nitrate), and then once again. The gold slag and ash pan were tested two times in order to recover the amount of silver lost from the 3 samples in the assay. On the one hand, the experimental values of various physical quantities are obtained according to the above mathematical model, and the content of silver in the sample is calculated by the proposed fire test gold weight method and mathematical correction method. The method is referred to as the method 1 for short. On the other hand, using the method contrast test, the results of the silver in the two test gold reclaimed slag Petri dish are corrected for the results of a test gold. Finally, the content of silver in each sample is obtained. This method is referred to as the method of 2 .

\subsubsection{Ingredient}

Various fluxes are proportioning according to the amount in table 1 .

\begin{tabular}{|c|c|c|c|c|c|c|c|c|}
\hline Assaying name & Sample name & Sample mass & $\mathrm{Na}_{2} \mathrm{CO}_{3}$ & $\mathbf{P b O}$ & $\mathrm{SiO}_{2}$ & Borax & Starch & $\mathrm{KNO}_{3}$ \\
\hline \multirow{3}{*}{1} & Crude copper & 10.00 & 25 & 300 & 20 & 5 & q.s. & \multirow{5}{*}{ q.s. } \\
\hline & Copper concentrate & 15.00 & 25 & 150 & 13 & 10 & & \\
\hline & Copper anode slime & 1.00 & 20 & 100 & 10 & 10 & q.s. & \\
\hline \multirow{2}{*}{2} & Slag & Full dose & 20 & 50 & 5 & 10 & 3.0 & \\
\hline & Cupel & Full dose & 20 & 50 & 10 & 20 & 3.5 & \\
\hline
\end{tabular}

Table 1. Assay ingredient scheme.

\subsubsection{Test Condition Control}

Smelting: $900^{\circ} \mathrm{C}$ into the furnace, 20 min heating to $900^{\circ} \mathrm{C}$ degrees, heat preservation $10 \mathrm{~min}$ after heating in $15 \mathrm{~min}$ to $1100^{\circ} \mathrm{C}$ degrees, heat preservation after $10 \mathrm{~min}$ out of the furnace. The quality of the two reclaimed lead button masss (including slag and ash) was 30 32 g.

Cupellation: $900^{\circ} \mathrm{C}$ centigrade ash preheating $30 \mathrm{~min}$, $840 \sim 850^{\circ} \mathrm{C}$ cupellation, before the end of heating to $860^{\circ} \mathrm{C}$ degrees. The ash is cement ash (the mass ratio of ash to cement is 1: 1). The crystal of the yellow feather like lead oxide around the ash after ash is large, except for the less copper.

\subsection{The Experimental Summary}

\subsubsection{The Experimental Values of the Physical Quantities in the Mathematical Model}

The experimental data of crude copper, copper concentrate and copper anode mud in the assay are shown in table 2 to table 3. Table 2 to table 3: $X_{2}=m-m_{1}-m_{2} ; X_{0}=X_{2}+Y_{1}+Y_{2} ; \lambda_{1}=X_{0} /$ $\left(X_{2}+Y_{2}\right) ; \lambda_{2}=\left(X_{2}+Y_{2}\right) / X_{2} ; \lambda=\lambda_{1} \times \lambda_{2} ; K_{\mathrm{D}}$ is calculated by 
formula (1), of which $\rho_{1}$ is calculated by $11.3 \mathrm{~g} / \mathrm{cm}^{3}$ effluent, and $\rho_{2}$ is the measured data after the slag is cooled to the solid;

$J$ is calculated according to formula (4), $A$ and $k$ are obtained by regression of formula (17) (where $X_{1}$ is equal to $X_{2}$ plus $Y_{2}$ ).

Table 2. The recovery results for coarse slag of copper, copper concentrate dish and copper anode slime.

\begin{tabular}{|c|c|c|c|c|c|c|c|c|c|c|}
\hline \multirow[b]{2}{*}{ Sample } & \multirow[b]{2}{*}{ Test No. } & \multirow{2}{*}{$\begin{array}{l}\text { Sample } \\
\text { quality } G / g\end{array}$} & \multirow[b]{2}{*}{$M / g$} & \multirow[b]{2}{*}{$W / \mathbf{g}$} & \multirow[b]{2}{*}{$Z / g$} & \multicolumn{4}{|c|}{ Composite granule of precious metal* } & \multirow{2}{*}{$\begin{array}{l}\text { Blank } \\
\text { silver } \\
m_{0} \% / m g\end{array}$} \\
\hline & & & & & & $\begin{array}{l}\text { Granule } \\
m / \mathrm{mg}\end{array}$ & Gold $m_{1} / \mathrm{mg}$ & $\begin{array}{l}\text { Palladium } \\
\mathrm{m}_{2} / \mathrm{mg}\end{array}$ & $\begin{array}{l}\text { Silver } \\
X_{2} / \mathbf{m g}\end{array}$ & \\
\hline \multirow{4}{*}{$\begin{array}{l}\text { Crude } \\
\text { copper }\end{array}$} & $\mathrm{A}_{1}$ & 10.00 & 1.5 & 35.2 & 310 & 17.400 & 1.759 & 0.487 & 15.154 & 0.300 \\
\hline & $\mathrm{A}_{2}$ & 10.00 & 2.8 & 51.4 & 293 & 17.555 & 1.762 & 0.489 & 15.304 & 0.300 \\
\hline & $\mathrm{B}_{1}$ & 10.00 & 1.8 & 38.6 & 306 & 36.427 & 1.637 & 0.224 & 34.566 & 0.300 \\
\hline & $\mathrm{B}_{2}$ & 10.00 & 3.0 & 53.6 & 290 & 36.638 & 1.641 & 0.225 & 34.772 & 0.300 \\
\hline \multirow{4}{*}{$\begin{array}{l}\text { Copper } \\
\text { concentrate }\end{array}$} & $\mathrm{C}_{1}$ & 15.00 & 19.2 & 38.5 & 163 & 9.781 & 0.003 & - & 9.778 & 0.150 \\
\hline & $\mathrm{C}_{2}$ & 15.00 & 15.8 & 52.0 & 148 & 9.730 & 0.003 & - & 9.727 & 0.150 \\
\hline & $\mathrm{D}_{1}$ & 15.00 & 18.5 & 41.6 & 159 & 16.915 & 0.009 & - & 16.906 & 0.150 \\
\hline & $\mathrm{D}_{2}$ & 15.00 & 15.0 & 55.7 & 144 & 16.944 & 0.010 & - & 16.934 & 0.150 \\
\hline \multirow{4}{*}{$\begin{array}{l}\text { Copper } \\
\text { anode slime }\end{array}$} & $\mathrm{E}_{1}$ & 1.0013 & 3.0 & 32.2 & 90 & 113.495 & 2.245 & 0.047 & 111.203 & 0.100 \\
\hline & $\mathrm{E}_{2}$ & 1.0005 & 4.3 & 47.9 & 73 & 113.236 & 2.235 & 0.048 & 110.953 & 0.100 \\
\hline & $\mathrm{F}_{1}$ & 1.0016 & 3.0 & 33.0 & 89 & 250.812 & 1.828 & 0.113 & 248.871 & 0.100 \\
\hline & $\mathrm{F}_{2}$ & 1.0002 & 4.5 & 50.3 & 71 & 250.263 & 1.835 & 0.115 & 248.313 & 0.100 \\
\hline \multirow[t]{2}{*}{ Sample } & Test No. & $\rho_{2} /\left(\mathrm{g} / \mathrm{cm}^{3}\right)$ & $Y_{1} / \mathrm{mg}$ & $Y_{2} / \mathrm{mg}$ & $X_{0} / \mathrm{mg}$ & $K_{\mathrm{D}}$ & $J$ & $\lambda_{1}$ & $\lambda_{2}$ & $\lambda$ \\
\hline & $\mathrm{A}_{1}$ & 5.35 & 0.311 & 0.498 & 15.963 & 936 & 443 & 1.0199 & 1.0329 & 1.0534 \\
\hline \multirow{3}{*}{$\begin{array}{l}\text { Crude } \\
\text { copper }\end{array}$} & $\mathrm{A}_{2}$ & 5.28 & 0.205 & 0.555 & 16.064 & 944 & 441 & 1.0129 & 1.0363 & 1.0496 \\
\hline & $\mathrm{B}_{1}$ & 5.33 & 0.636 & 0.907 & 36.109 & 938 & 442 & 1.0179 & 1.0262 & 1.0446 \\
\hline & $\mathrm{B}_{2}$ & 5.25 & 0.441 & 1.044 & 36.257 & 946 & 439 & 1.0123 & 1.0300 & 1.0427 \\
\hline \multirow{4}{*}{$\begin{array}{l}\text { Copper } \\
\text { concentrate }\end{array}$} & $\mathrm{C}_{1}$ & 5.15 & 0.105 & 0.339 & 10.222 & 895 & 408 & 1.0104 & 1.0347 & 1.0454 \\
\hline & $\mathrm{C}_{2}$ & 5.05 & 0.072 & 0.371 & 10.170 & 893 & 399 & 1.0071 & 1.0381 & 1.0455 \\
\hline & $D_{1}$ & 5.13 & 0.163 & 0.519 & 17.588 & 900 & 408 & 1.0094 & 1.0307 & 1.0404 \\
\hline & $\mathrm{D}_{2}$ & 5.08 & 0.110 & 0.584 & 17.628 & 916 & 412 & 1.0063 & 1.0345 & 1.0410 \\
\hline \multirow{4}{*}{$\begin{array}{l}\text { Copper } \\
\text { anode slime }\end{array}$} & $\mathrm{E}_{1}$ & 4.10 & 0.580 & 1.768 & 113.551 & 1500 & 544 & 1.0051 & 1.0159 & 1.0211 \\
\hline & $\mathrm{E}_{2}$ & 4.08 & 0.310 & 2.141 & 113.404 & 1540 & 556 & 1.0027 & 1.0193 & 1.0220 \\
\hline & $\mathrm{F}_{1}$ & 4.15 & 1.217 & 2.912 & 253.000 & 1519 & 558 & 1.0048 & 1.0117 & 1.0166 \\
\hline & $\mathrm{F}_{2}$ & 4.07 & 0.649 & 3.580 & 252.542 & 1520 & 548 & 1.0026 & 1.0144 & 1.0170 \\
\hline
\end{tabular}

Note: $M$ represents the quality of starch or potassium nitrate. *: Precious metal particles other than gold, silver and palladium are negligible.

Table 3. Characteristic constant related to assay conditions about sample, ingredients and cupellation.

\begin{tabular}{lllllll}
\hline Sample name & $\boldsymbol{Z}_{\mathbf{0}} / \mathbf{g}$ & $\boldsymbol{K}$ & $\overline{\boldsymbol{\rho}_{2} /\left(\mathbf{g} / \mathbf{c m}^{\mathbf{3}}\right)}$ & $\overline{\mathrm{K}_{\mathrm{D}}}$ & $\overline{\mathbf{J}}$ & $\boldsymbol{A}$ \\
\hline Crude copper & 348 & 0.5 & 5.30 & 941 & 441 & 0.0254 \\
Copper concentrate & 204 & $0.7 \sim 0.8$ & 5.10 & 901 & 407 & 0.00821 \\
Copper anode slime & 128 & 1.5 & 4.10 & 1520 & 0.00769 & 552 \\
\hline
\end{tabular}

As can be seen from table 2, $W$ is mainly determined by the amount of reducing agent (starch) or oxidant (potassium nitrate) added to the ingredients, and the change of $W$ will lead to the change of $Z$. In combination with table 2 and table 3 , it can be seen that $Z_{0}$ is determined by the amount of flux (mainly lead oxide) added to the ingredients; $\rho_{2}, K_{\mathrm{D}}$ or $J$ are mainly determined by the sample and the proportioning scheme (such as the silicic acid degree $K$ of the slag). The formula can be theoretically estimated from table 1: the silicic acid degree of copper anode slime slag is higher, about 1.5, which is greater than 0.5 of crude copper and $0.7 \sim 0.8$ of copper concentrate, so the slag density of copper anode slime is lower and the content of heavy metal elements is lower, so that the affinity of slag and silver is smaller, and the lead button mass also has low impurity content. The $K_{\mathrm{D}}$ value of copper anode slime is much larger than that of crude copper and copper concentrate.

\subsubsection{Comparison Test of Method 1 and Method 2}

\section{(i) Analysis Results}

In order to verify the amount of silver loss of different kinds of samples, different content of silver and the size of lead button mass, the amount of silver loss in the test is consistent with the mathematical model (6), (18) and (20) established by the experiment. According to the 12 times a total of 6 samples in Table 2, the silver content $X_{2}$ and the mass of lead button mass were $W$. The correction coefficient of the silver in the slag, the ash and the total loss was calculated. The results of the method 1 were calculated $\left(W_{1}\right)$, and the results of method 2 were compared with the results of method $2\left(W_{2}\right)$. The results were shown in Table 4. 
Table 4. The results table of silver.

\begin{tabular}{|c|c|c|c|c|c|c|c|c|}
\hline \multirow{2}{*}{$\begin{array}{l}\text { Sample } \\
\text { name }\end{array}$} & \multirow{2}{*}{ Test No. } & \multicolumn{3}{|l|}{ Method 1} & \multicolumn{3}{|l|}{ Method 2} & \multirow{2}{*}{$\begin{array}{l}\text { Relative } \\
\text { difference } / \%\end{array}$} \\
\hline & & Loss of slag & Cupel of losses & $w_{1}$ & Loss of slag & Cupel of losses & $w_{2}$ & \\
\hline \multirow{4}{*}{$\begin{array}{l}\text { Crude } \\
\text { copper }\end{array}$} & $\mathrm{A}_{1}$ & 30.7 & 49.7 & 1565 & 31.1 & 49.8 & \multirow{2}{*}{1571} & -0.38 \\
\hline & $\mathrm{A}_{2}$ & 20.0 & 55.1 & 1574 & 20.5 & 55.5 & & +0.19 \\
\hline & $\mathrm{B}_{1}$ & 63.3 & 92.3 & 3581 & 63.6 & 90.7 & \multirow{2}{*}{3588} & -0.20 \\
\hline & $\mathrm{B}_{2}$ & 43.6 & 102.2 & 3592 & 44.1 & 104.4 & & +0.11 \\
\hline \multirow{4}{*}{$\begin{array}{l}\text { Copper } \\
\text { concentrate }\end{array}$} & $\mathrm{C}_{1}$ & 6.9 & 22.9 & 671 & 7.0 & 22.6 & \multirow{2}{*}{670} & +0.15 \\
\hline & $\mathrm{C}_{2}$ & 4.6 & 24.4 & 667 & 4.8 & 24.7 & & -0.45 \\
\hline & $D_{1}$ & 10.8 & 35.4 & 1163 & 10.9 & 34.6 & \multirow{2}{*}{1164} & -0.09 \\
\hline & $\mathrm{D}_{2}$ & 7.4 & 38.0 & 1164 & 7.3 & 38.9 & & 0.00 \\
\hline \multirow{4}{*}{$\begin{array}{l}\text { Copper } \\
\text { anode } \\
\text { slime }\end{array}$} & $\mathrm{E}_{1}$ & 598 & 1810 & 113367 & 579 & 1766 & \multirow{2}{*}{113.276} & +0.08 \\
\hline & $\mathrm{E}_{2}$ & 327 & 2074 & 113191 & 310 & 2140 & & -0.08 \\
\hline & $F_{1}$ & 1281 & 2907 & 252546 & 1215 & 2907 & \multirow{2}{*}{252.444} & +0.04 \\
\hline & $\mathrm{F}_{2}$ & 680 & 3525 & 252357 & 649 & 3579 & & -0.03 \\
\hline
\end{tabular}

As shown in Table 4, the values of the two methods are basically the same. The relative difference between the results of the method 1 and the method 2 for the determination of the results of the two samples of copper and copper concentrate is within $\pm 0.5 \%$, and the copper anode slime is within $\pm 0.1 \%$.

\section{(ii) Precision}

One of the samples of coarse copper and copper concentrate was selected respectively. The reliability of method 1 was verified further, and the comparison test was carried out by method 2. The results of the first test of silver, the results of theoretical correction and the results of the actual recovery and correction are shown in Table 5.

\section{(a) Precision Test of Crude Copper}

A total of 11 crude copper $10 \mathrm{~g}$ samples were taken in parallel and $2.2 \mathrm{~g}$ starch was added. The other experimental conditions were carried out in 2.2 sections. The quality $W$ of the buckle was $40.5 \mathrm{~g} \sim 43.5 \mathrm{~g}$ through one test gold, the mass
$X_{2}$ of the silver in the aggregate was $9.970 \mathrm{mg}$ to $10.230 \mathrm{mg}$, the blank silver $m_{0}{ }^{\prime}$ was $0.720 \mathrm{mg}$, and the silver quality in the two times of two test gold reclaimed slag was $0.380 \mathrm{mg}$ to $0.520 \mathrm{mg}$. It is visible from table 5 that the relative standard deviations $(R S D, \mathrm{n}=11)$ of method 1 and method 2 are $0.9 \%$ and $1.2 \%$, respectively.

\section{(b) Precision Test of Copper Concentrate}

A total of 12 samples of $15 \mathrm{~g}$ copper concentrate and $19 \mathrm{~g}$ $\mathrm{KNO}_{3}$ were added in parallel. The other experimental conditions were carried out in 2.2 sections. The quality $W$ of the buckle was $40.3 \mathrm{~g} \sim 42.5 \mathrm{~g}$ through one test gold, the mass $X_{2}$ of the silver in the aggregate was $1.805 \mathrm{mg}$ to $1.877 \mathrm{mg}$, the blank silver $m_{0}{ }^{\prime}$ was $0.155 \mathrm{mg}$, and the silver quality of the recycled slag petri dish two times was $0.096 \mathrm{mg}$ to $0.180 \mathrm{mg}$. It is visible from table 5 that the relative standard deviations $(R S D, \mathrm{n}=12)$ of method 1 and method 2 are $1.2 \%$ and $1.0 \%$, respectively.

Table 5. Results of precision test.

\begin{tabular}{|c|c|c|c|c|c|c|c|}
\hline Sample & Method. & $\begin{array}{l}\text { Found by one time } \\
\text { assaying } /(g / t)\end{array}$ & $\begin{array}{l}\text { Average } \\
/(g / t)\end{array}$ & $\begin{array}{l}\text { RSD } \\
/ \%\end{array}$ & $\begin{array}{l}\text { After correction Found } \\
/(\mathrm{g} / \mathrm{t})\end{array}$ & $\begin{array}{l}\text { Average } \\
/(g / t)\end{array}$ & $\begin{array}{l}\text { RSD } \\
1 \%\end{array}$ \\
\hline Crude copper & 1 & $949,947,952,942$ & \multirow{2}{*}{937.4} & \multirow{2}{*}{1.0} & \multirow{2}{*}{$\begin{array}{l}1,000,999,1,004,994,991 \\
978,983,976,985,978,988 \\
1,005,1,000,999,996,988 \\
975,975,970,994,986,992\end{array}$} & 988.7 & 0.9 \\
\hline$(n=11)$ & 2 & $\begin{array}{l}940,927,932,925 \\
934,927,936\end{array}$ & & & & 989.1 & 1.2 \\
\hline Copper & 1 & $\begin{array}{l}110.0,111.8,114.1 \\
111.3,113.2,110.7\end{array}$ & & 12 & $\begin{array}{l}117.1,119.0,121.3,118.4,120.5,117.8 \\
122.2,119.4,119.3,118.7,119.3,119.0\end{array}$ & 119.3 & 1.2 \\
\hline
\end{tabular}

\section{Result and Discussion}

\subsection{Essentials of the Operation of the Analysis of the Test Gold}

\subsubsection{Smelting and Ingredient}

According to the experiment, the loss regularity of silver in smelting process (5) and formula (4) are known as the following 3 rules.

First: The loss of silver in smelting slag $Y_{1}$, first of all, is directly related to the silver content $X_{0}$ in the sample, that is, proportional to the total slag volume $Z_{0}$ and the mass $W$ of the lead button mass, reducing $Z_{0}$ or increasing $W$, which can reduce the $Y_{1}$. In general, the more amount of acid and alkali flux, the more complete the sample decomposition, the more pure lead button mass, which is favorable for the analysis of the test gold, and the amount of slag produced by this increase, the loss of silver in the slag is also increased, which is unfavorable. But if the amount of the added acid and alkali flux is too small, it will not guarantee the complete degree of the sample decomposition, even the quality of the slag and the lead button mass [1, 2, 13], which will not ensure the correctness of the test result. Therefore, the amount of acid and alkali flux added to the ingredients must be reduced as much as possible, on the premise of ensuring the complete decomposition of the sample, the quality of the slag and the 
quality of the lead button mass. If the lead is too small, the amount of loss in the slag will be significantly increased because of the incomplete collection of precious metals, which leads to a larger analysis result. Although the greater the lead button mass, the enrichment and recovery of precious metals is beneficial, but it will have adverse effects on the removal of lead in the post process. In addition, the size of the lead button mass is also restricted by the size and material of the dish (that is, the limit on the absorptive capacity of lead oxide). It is known from table 2 that the lead button mass is usually controlled at 30 50 g.

Second: $Y_{1}$ has a certain relationship with the density of the slag and the distribution coefficient $K_{\mathrm{D}}$ of the silver. In theory, $\rho_{2}$ and $K_{\mathrm{D}}$ are only related to the composition and characteristics of the slag (such as silicidity, impurity and so on). When the sample and the ingredients are determined, they should be fixed. However, in the actual test, $K_{\mathrm{D}}$ is also related to the uniformity of test materials and smelting mode, such as the specific surface area of the "lead rain", the time of the "lead rain" in the molten body and the temperature of the molten body. Because the thinner the "lead rain" is, the larger the specific surface area is, the longer the time in the molten body is kept, the greater the probability of the contact between the molten metal lead and the precious metals exposed in the sample decomposition process. This enriching effect is better, that is, the larger the $K_{\mathrm{D}}$, the smaller the $Y_{1}$. So in the batching operation, the sample, acid and alkali flux, collector, reducing agent or oxidizer should be grinded and stirred even as much as possible. In the process of melting, borax can make the slag become sticky at about $900^{\circ} \mathrm{C}$. If the heat preservation can prevent the excessive precipitation of lead rain, it is beneficial to improve the effect of lead on the collection of precious metals. Therefore, it is generally used to keep the heat of 5 10 min at about $900^{\circ} \mathrm{C}$ after slow heating up. After $950^{\circ} \mathrm{C}$, the viscosity of the slag is greatly reduced, and with the thinning of the slag, the "lead rain" will settle rapidly. At this time, the heating rate can be improved properly, which is beneficial to the process of slag making and the separation of the slag.

Third: In the analysis of lead test, the lead button mass and slag can be said to be the "dragon and phoenix births" of the same birth, which both influence and inseparable, and their quality is determined by the blending scheme, the purity of the reagents $[1$, $2,14]$, the granularity and uniformity of the test material, and the melting method. Good lead button mass must be based on ideal slag. Without ideal slag, it is impossible to produce a good lead button mass. Ideal slag includes ideal composition, quantity and characteristics, and good lead clasp includes good quality and proper size, while the quality and size of the lead will directly affect the quantity, composition and characteristics of the slag. Because there are many non idealized conditions and conditions in the actual operation, the $K_{\mathrm{D}}$ value measured by the experiment is usually smaller than its theoretical value.

\subsubsection{Cupellation}

The loss regularity of silver in the cupellation process (19) shows that the loss of silver in the ash $\left(Y_{2}\right)$ is the main direct relationship with the actual content $\left(X_{1}\right.$ or $\left.X_{2}\right)$ in the lead button mass, and the second is related to the size of the lead button mass. The longer the lead button mass, the longer the time it takes, the more the loss of silver (including the loss in the ash and the loss of the volatilization of the high temperature) during the cupellation process. The smaller the lead button is, the less the ash blow loss is, but it must be based on the premise that the enrichment of precious metals in the molten sample is ensured.

In the process of cupellation, cupellation temperature has great influence on silver loss $[1,2,15]$. Therefore, strict and effective supervision and control must be carried out. The cupellation temperature is usually measured and displayed by automatic temperature control instrument, but it has a great relationship with the location of the end of the thermocouple, the ventilation in the muffle furnace, and the heating and cooling of the cupellation. Therefore, the temperature measured by the temperature control instrument has a great relativity. It only represents the temperature of the test point at the end of the thermocouple, but does not represent the actual reaction temperature of the surface of the lead molten body when the ash is blown. Therefore, as a fire assay analyst, we must learn how to judge whether the cupellation temperature is reasonable or not according to the phenomenon of dust blowing. Such as the color of the furnace, the luster of the molten lead and the appearance and change of the crystal surrounding the dish. For the samples with normal cupellation, it is necessary to ensure that there is a clear feather like yellow lead oxide crystallization around the ash cement ash, otherwise the cupellation temperature may be higher. It is important to note that for the samples containing high copper (such as coarse copper), because the copper content in the lead button mass is relatively high, it is necessary to improve the cupellation temperature properly to ensure the smooth oxidation and removal of the copper in the cupellation. When the magnesia ash pan is blown, it is also necessary to increase the cupellation temperature. Otherwise, it will easily lead to residual grain lead or high impurity content. In addition, the ash blow loss of silver is also related to the material, ratio and process of the ash [10, 11, 12] such as the magnesia ash is usually smaller than the ash of ash cement, so the ash recovery rate is higher.

\subsection{The Quality of the Best Lead Button Mass and Its Significance}

\subsubsection{The Definition of the Lead Button Mass of Best Quality}

The precision and accuracy of the analytical method are usually determined by the recovery rate of the elements to be measured in the analysis process. The smaller the general loss, the higher the recovery rate (except the case of over 100\%, that is, the closer to $100 \%$ ), the higher the accuracy is, the higher the recovery rate is, the smaller the range of the fluctuation of the amount of element loss to be measured, the higher the precision. In order to make the precision and accuracy of the lead test weight method to measure the precision and accuracy of silver, the quality of the lead button masss needed to be controlled in the actual operation is discussed as follows. 
From the formula (5) and formula (19), it is known that, on the premise of ensuring the complete decomposition of the sample and the quality of the lead button mass, in order to improve the capture effect of the lead button mass to the silver (that is, Y1), the mass of the lead button mass should be increased by $\mathrm{W}$, that is, the formula (5) is the decrease function of the Y1 on the W. In order to reduce the loss of Y2 in the process of silver blowing, the mass of the lead button mass should be reduced by W, that is, formula (19) is an increasing function of $\mathrm{Y} 2$ on W. According to the concept and meaning of function derivative in higher mathematics, when [Y1 (W) $+\mathrm{Y} 2(\mathrm{~W})]^{\prime}=0$ is $\mathrm{Y} 1(\mathrm{~W}){ }^{\prime}=-\mathrm{Y} 2(\mathrm{~W})^{\prime}$, the value of $(\mathrm{Y} 1+\mathrm{Y} 2)$ is minimum, and the recovery rate of the method is relatively stable and the highest (that is, the precision and accuracy of lead test silver is the best). As a result, the calculation formula of the best theoretical lead mass $\mathrm{W} 0$ is as follows.

$$
W_{0}=\frac{1-k}{k \times(J-1.077)} \times Z \approx \frac{Z_{0}}{k \times J}(0<k<<1, \mathrm{~J}>>1)
$$

The formula (22): $Z_{0}$ and $J$ mainly depend on the samples and ingredients, and $k$ is related to the factors such as the cupellation temperature, the material of the ash, and the manufacturing process. When the proportioning scheme and the cupellation condition are fixed, $W_{0}$ is the fixed value, and the value is defined as the best quality of lead button mass.

\subsubsection{The Significance of the Quality of the Best Lead Button Mass}

According to the data of $Z_{0}, J$ and $k$ in Table 3, the best quality of lead button mass under different test materials, such as crude copper, copper concentrate and copper anode slime, can be calculated by formula (22). Meanwhile, the crude copper [16, copper concentrate [17] and copper anode slime [18 is compared with the national or industry standard fire test weight method, and the quality of the recommended lead button mass in 18 is compared. See Table 6.

Table 6. Control with different samples and ingredients scheme to lead.

\begin{tabular}{|c|c|c|c|c|c|}
\hline \multirow{2}{*}{ Sample No. } & \multicolumn{2}{|l|}{ Method 1} & \multirow{2}{*}{$\begin{array}{l}\text { The optimal lead } \\
\text { button mass }\end{array}$} & \multicolumn{2}{|l|}{ Lead button mass } \\
\hline & Lead oxide dosage & $Z_{0}$ & & Recommended by standard method & Recommended by proposed method \\
\hline Crude copper & 300 & 348 & 95.6 & $30 \sim 40$ & $40 \sim 50$ \\
\hline Copper concentrate & 150 & 204 & 64.8 & $30 \sim 45$ & $40 \sim 50$ \\
\hline Copper anode & $80 *$ & 105 & 32.5 & $25 \sim 40$ & $30 \sim 35$ \\
\hline slime & 100 & 128 & 39.6 & $32 \sim 50$ & $35 \sim 40$ \\
\hline
\end{tabular}

*: the standard method $Y S / T$ 745.2-2010 recommendation.

The table 6: when the copper anode slime is tested, the test is carried out at the amount of lead oxide 80 (standard method [18] recommended) and $100 \mathrm{~g}$ respectively. The amount of other tests is tested in accordance with the recommended amount of standard method [16-17]

The standard method YS/T 521.2 - 2009 [19] (after removing copper by wet sulfuric acid and then measuring the fire test weight method) can not only increase the weight of the sample, but also reduce the use of lead oxide. The representation of the symmetrical sample, the method sensitivity (detection limit), the accuracy and stability of the result are also very favorable, so it is suitable for arbitration. Analysis or use as a standard analysis method. However, the analysis process is long and it is difficult to carry out large scale scale analysis. Although the recovery rate of the standard method $S N / T 1789$ - 2006 [16] is relatively low, it has the advantages of simple operation and short detection period, which is suitable for large-scale analysis of large quantities of samples. The standard method SN/T 1789-2006, in order to ensure the representative of the sample (called sample $10 \mathrm{~g}$ ) and the melting sample, can remove a large amount of copper by separating the slag from the slag to obtain a more pure lead button mass. A large amount of lead oxide is added to the burden, which will lead to the increase of the amount of molten slag $Z_{0}$, resulting in a significant increase in the loss of gold and silver in the slag. Therefore, in order to improve the recovery rate of precious metals in smelting slag, it is suggested that the quality of the lead button mass should be increased properly. According to the optimal lead mass $\left(W_{0}=95.6 \mathrm{~g}\right)$ calculated by this mathematical model, the data $(30 \sim 40 \mathrm{~g})$ given by the standard method SN/T 1789-2006 is relatively small, but considering the actual grey dish specifications (the standard method [16-19] uniform specifications are: the top diameter is $35 \mathrm{~mm}$, the bottom diameter is $40 \mathrm{~mm}$, the height is about $30 \mathrm{~mm}$, and the depth is about $17 \mathrm{~mm}$. The mass of ash cement before heat is about $55 \mathrm{~g}$, and the mass of magnesia ash is about $75 \mathrm{~g}$ because of its larger density. The limitation of the absorptive capacity of lead oxide and its ash (the absorption limit of the magnesia ash is $2 / 3$ of its weight, the cement ash is $3 / 4$, and the bone powder ash is about [ 1 of its weight. "Therefore, when the lead button mass is more than $55 \mathrm{~g}$, it is not good for the normal operation of the cupellation. Therefore, it is suggested that the quality of the lead button mass is $40 \sim 50 \mathrm{~g}$ for the determination of the lead button mass in the coarse copper. The standard method $G B / T$ 3884.2 - 2012 [17] stipulates that the quality of the lead button mass is $30 \sim 45 \mathrm{~g}$. The best lead button mass quality obtained according to the mathematical model proposed in this article is $64.8 \mathrm{~g}$. According to the above analysis, it is suggested that the quality of the lead button mass in the copper concentrate is also $40 \sim 50 \mathrm{~g}$. In the same $Y S / T$ $745.2-2010$ [18], the quality of lead button mass is $25 \sim 40 \mathrm{~g}$, the best lead button mass quality is $32.5 \mathrm{~g}$ when lead oxide is $80 \mathrm{~g}$, and the best lead button mass quality is $39.6 \mathrm{~g}$ when lead oxide is $100 \mathrm{~g}$. Therefore, it is suggested that the quality 
of lead button mass in the copper anode slime is respectively $30 \sim 35 \mathrm{~g}$ and 35 40 g respectively.

It can be seen from table 6 that, in addition to copper anode slime, whether crude copper or copper concentrate, in order to further improve the recovery rate of silver in the analysis of test gold, the precision and accuracy of the results are optimized. When the quality of lead button mass is not more than $55 \mathrm{~g}$ (that is, under the premise of the ash absorption limit of lead oxide), the quality of the lead button mass should not be small. In addition, according to the formula (22), when the amount of lead oxide and other fluxes is needed to be increased, the $W_{0}$ increases because the amount of slag $Z_{0}$ increases. When the samples of high grade silver are detected, the loss rate of cupellation decreases with the increase of the aggregate of the cupellation, that is, the $W_{0}$ needs to be increased, and the use of magnesia ash instead of the ashes is to be used. When the loss of silver in the ash is reduced, the recovery rate of cupellation rises, the same $k$ decreases, and the $W_{0}$ should be increased.

\subsection{Correction Coefficient of Silver Loss in the Fire Test Gold Analysis}

In order to display the quantitative law of silver loss in the analysis process of lead test in the analysis process of different sample ingredients, unequal silver content and lead mass in the analysis process of lead test, according to the experimental data of the selected experimental conditions (see experimental part) and $Z_{0}, J, A$ and $k$ in table 3 , the correction of silver in slag, ash and total loss is calculated separately (6), (18) and (20) respectively. The coefficients (i.e., $\lambda_{1}, \lambda_{2}$ and $\lambda$ ) are found in table 7 .

Table 7. The correction coefficient of silver in lead assay analysis.

\begin{tabular}{|c|c|c|c|c|c|c|c|c|c|}
\hline \multicolumn{10}{|c|}{ (I) Crude copper ( $G=10 \mathrm{~g}$ ) } \\
\hline \multirow{2}{*}{$w /(g / t)$} & \multicolumn{3}{|c|}{$W=30 \mathrm{~g}$} & \multicolumn{3}{|c|}{$W=40 \mathrm{~g}$} & \multicolumn{3}{|c|}{$W=\mathbf{5 0} \mathrm{g}$} \\
\hline & $\lambda_{1}$ & $\lambda_{2}$ & $\lambda$ & $\lambda_{1}$ & $\lambda_{2}$ & $\lambda$ & $\lambda_{1}$ & $\lambda_{2}$ & $\lambda$ \\
\hline 500 & 1.024 & 1.041 & 1.066 & 1.017 & 1.043 & 1.061 & 1.013 & 1.045 & 1.059 \\
\hline 1000 & 1.024 & 1.035 & 1.060 & 1.017 & 1.037 & 1.055 & 1.013 & 1.039 & 1.053 \\
\hline 2000 & 1.024 & 1.029 & 1.054 & 1.017 & 1.032 & 1.049 & 1.013 & 1.034 & 1.047 \\
\hline 3000 & 1.024 & 1.026 & 1.050 & 1.017 & 1.028 & 1.046 & 1.013 & 1.030 & 1.044 \\
\hline 4000 & 1.024 & 1.023 & 1.048 & 1.017 & 1.026 & 1.044 & 1.013 & 1.028 & 1.041 \\
\hline 5000 & 1.024 & 1.021 & 1.046 & 1.017 & 1.024 & 1.042 & 1.013 & 1.026 & 1.039 \\
\hline
\end{tabular}

\begin{tabular}{|c|c|c|c|c|c|c|c|c|c|}
\hline \multicolumn{10}{|c|}{ (II) Copper concentrate $(G=15$ g) } \\
\hline \multirow{2}{*}{$w /(g / t)$} & \multicolumn{3}{|c|}{$W=\mathbf{3 0} \mathrm{g}$} & \multicolumn{3}{|c|}{$W=40 \mathrm{~g}$} & \multicolumn{3}{|c|}{$W=50 \mathrm{~g}$} \\
\hline & $\lambda_{1}$ & $\lambda_{2}$ & $\lambda$ & $\lambda_{1}$ & $\lambda_{2}$ & $\lambda$ & $\lambda_{1}$ & $\lambda_{2}$ & $\lambda$ \\
\hline 300 & 1.014 & 1.039 & 1.054 & 1.010 & 1.042 & 1.052 & 1.008 & 1.043 & 1.051 \\
\hline 600 & 1.014 & 1.034 & 1.048 & 1.010 & 1.036 & 1.046 & 1.008 & 1.038 & 1.046 \\
\hline 1000 & 1.014 & 1.030 & 1.044 & 1.010 & 1.032 & 1.042 & 1.008 & 1.034 & 1.042 \\
\hline 1500 & 1.014 & 1.027 & 1.041 & 1.010 & 1.029 & 1.039 & 1.008 & 1.030 & 1.038 \\
\hline 2000 & 1.014 & 1.024 & 1.039 & 1.010 & 1.027 & 1.037 & 1.008 & 1.028 & 1.036 \\
\hline 3000 & 1.014 & 1.021 & 1.036 & 1.010 & 1.023 & 1.034 & 1.008 & 1.025 & 1.033 \\
\hline
\end{tabular}

\begin{tabular}{|c|c|c|c|c|c|c|c|c|c|}
\hline \multicolumn{10}{|c|}{ (III) Copper anode slime ( $G=1 \sim 2 \mathrm{~g})$} \\
\hline \multirow{2}{*}{$m /(\mathbf{m g})$} & \multicolumn{3}{|c|}{$W=\mathbf{3 0} \mathbf{g}$} & \multicolumn{3}{|c|}{$W=40 \mathrm{~g}$} & \multicolumn{3}{|c|}{$W=\mathbf{5 0} \mathbf{g}$} \\
\hline & $\lambda_{1}$ & $\lambda_{2}$ & $\lambda$ & $\lambda_{1}$ & $\lambda_{2}$ & $\lambda$ & $\lambda_{1}$ & $\lambda_{2}$ & $\lambda$ \\
\hline 60 & 1.006 & 1.019 & 1.025 & 1.004 & 1.021 & 1.025 & 1.003 & 1.022 & 1.025 \\
\hline 100 & 1.006 & 1.016 & 1.022 & 1.004 & 1.018 & 1.022 & 1.003 & 1.019 & 1.022 \\
\hline 150 & 1.006 & 1.014 & 1.020 & 1.004 & 1.016 & 1.020 & 1.003 & 1.017 & 1.020 \\
\hline 200 & 1.006 & 1.012 & 1.018 & 1.004 & 1.014 & 1.018 & 1.003 & 1.015 & 1.018 \\
\hline 400 & 1.006 & 1.008 & 1.014 & 1.004 & 1.010 & 1.014 & 1.003 & 1.011 & 1.014 \\
\hline
\end{tabular}

The analysis of data in table 7 shows that $\lambda_{1}$ is directly related to the sample burden and the size of lead button mass, but is not related to the silver content in the sample; the content of silver in the sample is the main influencing factor for $\lambda_{2}$, and the quality of the lead button mass has a certain relationship with the $\lambda_{2}$, but it is a secondary factor; the effect of the mass of lead button mass on the $W$ the force is less than $\lambda_{1}$ or $\lambda_{2}$.

\section{Conclusions}

When the lead test gold weight method is used to determine the silver in the sample, it is usually necessary to use two or three times for the recovery of [16-19] for the precious metals lost in the slag and ash. Although the analysis results are objective and true, the analysis process will be longer, the cost is higher, and the operation error risk (such as the pollution of precious metals, operation, etc.) And 
it also increases. According to the law of silver loss revealed in this paper, only one test gold can be carried out according

$$
\lambda=e^{A}\left(\frac{W}{X_{2}}\right)^{k}+\frac{Z_{0}}{W \times J}-\frac{1.077}{J} \text { and } w(\mathrm{Ag})=\left(\lambda \times X_{2}-m_{0}{ }^{\prime}\right) / \mathrm{G} \times 10^{3}
$$

for the loss of silver in the slag and ash, to make a scientific and effective correction, which is a good solution to the complicated operation and the increase of error caused by the above two or three test gold.

The composition, property and quantity of the slag can be changed with the change of the composition, properties and quantity of the slag, and the $K_{\mathrm{D}}, Z_{0}$ and $\rho_{2}$ will change with it. Finally, it will directly affect the $J$ and the $\lambda_{1}$, and the regression curve of cupellation loss after cupellation temperature, cupellation speed, ash material (including ratio, process) and so on Line type (17) will also shift, which will affect $A$ and $k$ and further affect $\lambda_{2}$. Therefore, the necessary adjustment or confirmation of the experimental data such as $Z_{0}, J, A$ and $k$ in the formula must be made to ensure the continuous application and effectiveness of the formula (6) and (18) for the calculation formula of the silver correction coefficient after the change or deviation of the blending scheme, the cupellation temperature and the material of the ash.

\section{References}

[1] И. Н. Pro. Sampling and test analysis [M]. Beijing: Metallurgical Industry Press, 1959:9.

[2] CAI Shu-xing, HUANG Chao. Analysis of precious metals [M]. Beijing: metallurgical industry press, 1984:4.

[3] SHENG Jian-lin. Application of computer in lead-test Gold ingredients [J]. Gold, 1999,11(8):41-45.

[4] XU Cun-sheng. Practice of fire test analysis work [J]. Gold, 1997,18 (9): 53-56.

[5] RONG Sha-sha, Niu Jin. Detailed discussion on the operation of lead gold testing method [J]. Low-carbon world, 2015(25):149-150.

[6] TANG Wen-hui. The possible errors in the analysis of fire gold and the measures to be taken. [J]. Gold, 1991,12 (6): 62-63.

[7] XIAO Wen-kang and ZHANG Wen-gang. Error source analysis of the determination of gold and silver content in copper concentrate by fire gold assay [J]. New technology and products of China, 2013(16):159-159.

[8] JIANG Shui-ying, XIAO Hua yun, WU Sheng-dong, WU Bo, QIN Yun-he. Evaluation of uncertainty of determination of gold content in copper concentrate by fire assay method $[\mathrm{J}]$. Rock ore test, 2008,27(4):299-301.

[9] YANG Zuo-ge, HE Ming-zhong. Improved the precision and accuracy of Gold determination in copper concentrate $[\mathrm{J}]$. Gold, 2002,23(3):40-43.

[10] SHENG Jian-lin. Cupellation loss of silver in silver assay and its correction [J]. Chinese Journal of Analysis Laboratory, 1992,11 (4): 66-68. to the mathematical formula

[11] CHEN Li-qing, WANG Ping, ZHANG Li-ming. Silver correction by using magnesium sand cupel in pyro-assa-ying [J]. Copper Engineering, 2003(2):73-75.

[12] SHENG Jian-lin. Research on the effect of ash material on the analysis results $[\mathrm{J}]$. Chinese Journal of Analysis Laboratory, 2009,28 (z1): 282-285.

[13] MA Li-jun, LI Zheng-xu, ZHONG Yi-nan, KAN Chun-hai, XIAO Qian-peng. Discussion on the influence of impurity elements on the determination of Gold content in crude Gold by fire Gold weight method [J]. Gold, 2017,38(4):73-76.

[14] JIANG Xin. Analysis of the influence of sample size on the analysis results of gold and silver in copper concentrate by fire gold assay [J]. Science and technology and innovation, 2014(11):7-8.

[15] ZHANG Meng-jie, HOU Bao-jun, ZHOU Zhi-ming, WU Bai-yang. Effects of different ash blowing temperatures on the detection results of lead fire assay [J]. China test, 2015, 23(4):12-14.

[16] [16]People's Republic of China State General Administration of quality supervision, inspection and quarantine. SN/T 1789-2006, determination of gold and silver in coarse copper, fire test weight method [S]. Beijing: China Standard Press, 2006.

[17] People's Republic of China State Administration for quality supervision, inspection and quarantine, China National Standardization Management Committee, GB/T 3884.2- 2012 copper concentrate chemical analysis methods second parts: Determination of gold and silver content, flame atomic absorption spectrometry and fire test method [S].: China Standard Publishing Agency, 2012.

[18] Department of industry and information technology of People's Republic of China. YS/T 745.2-2010 copper anode slime chemical analysis method: second part: Determination of gold and silver content of fire test gold weight method [S].: China Standard Press, 2010 .

[19] Department of industry and information technology of People's Republic of China. YS/T 521.2-2009 method for chemical analysis of crude copper, part second: Determination of gold and silver, fire test weight method [S]., Beijing: China Standard Press, 2009.

\section{Biography}

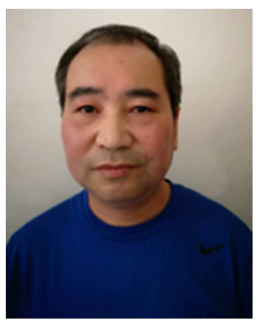

Sheng Jianlin (1963-) male, senior technician. In 1985, I graduated from changsha non-ferrous metal college, hunan, majoring in analytical chemistry. For more than 30 years, the fire assay has been engaged in the determination of gold and silver palladium and other precious metal elements analysis and research. Currently, he is the technical director and authorized signatory of the fire test gold group in the testing center of zhejiang fuye group co., LTD. 